\section{From the Desk of the Editor}

\section{Season's greeting and Happy New year 2014}

\section{K. S. Gopinath}

Published online: 4 February 2015

(C) Indian Association of Surgical Oncology 2015

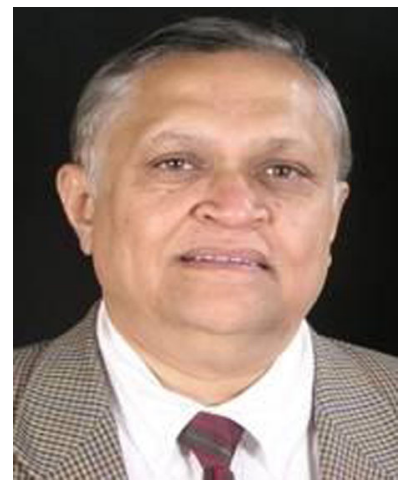

I would like to take this wonderful opportunity to wish you all a merry Christmas and a prosperous healthy New Year. Now we are completing five years of our publication and I would like to thank the office of Indian Association of Surgical Oncology, it's Executive and Editorial board members for their co operation in bringing out the journal successfully even during difficult times. We have a good team who are working very efficiently to move on and more importantly to move forward.

It is important for us to define our goals clearly so that we will improve publication status to improve the academic standing, and enter into global leadership along with other oncology journals. Recently we had a meeting with editor of European Journal of Oncology (Prof. Graham Posten, Prof. Audisio) and with Prof. Charles Balsch of Annals of Surgical Oncology to come

K. S. Gopinath $(\bowtie)$

HCG - Bangalore Institiute of Oncology, Bangalore \& Prof. of Surgery \& Oncology, Sri Devaraj Urs Medical College, Kolar. No. 20, Srinivasa Behind Balaji Kalyana Mantapam, BSK III Stage, Bangalore 560085, India

e-mail: gopiijso@gmail.com together and have a clear partnership for progress of oncology across the globe.

I see many challenges in the coming two years, but in these challenges there are opportunities to make a difference. Perhaps the main challenge may appear to be having too much that needs to be done. Our area of interest at presently prioritizing our objectives on improving the academic standing of IJSO.

I recognize and appreciate the members of IASO and non members who contributed to the development of IJSO. I sincerely thank authors, reviewer's who had spent their valuable time in helping us to bring the journal successfully for the last five years.

I appeal to all oncology trainees, residents, fellows and young faculty to get involved in publication process to enhance the academic standards for themselves and to the journal.

I intend to run the journal in more democratic manner and your constructive criticism is always appreciated. I am happy to mention that majority of the Articles published for the other two years is the work done by the members and not borrowed from any journal. In this issue we have combination of various original articles, review, case reports and advanced technology. This issue also addresses the various interesting case reports and their management.

I congratulate Dr. K. Harish Prof. of Surgical Oncology at M.S. Ramaiah Medical College, Bangalore, India getting elected as an associate editor. I thank the editorial board, office of IJSO Mr. Suresha J (Dayandanda Sagar College of Engineering), Dr. Shivananda Swamy whose hard work as given an outstanding status for the journal.

With regards,

Prof. K.S. Gopinath

Ambuja Health Care 